\author{
Дискурсивное конструирование \\ текущих российско-кубинских отношений \\ в онлайн-материалах кубинского информационного агентства \\ «Пренса Латина» (“PL”)
}

\author{
Барселай Рамирес Ярилейси
}

\begin{abstract}
Аннотация. Цель исследования - выявить лексические средства дискурсивного конструирования современных российско-кубинских отношений (с 2000 года по настоящее время) в содержании онлайнматериалов кубинского информационного агентства «Пренса Латина» (далее - “PL”). Новизна исследования заключается в том, что впервые и на основе комплексной методики проводится глубокий анализ дискурсивного конструирования нынешних российско-кубинских отношений, включающий методы дискурс-анализа и контент-анализа, что позволяет показать конструктивное видение отражения этих отношений в современных геополитических условиях. В результате было выявлено, что в материалах "PL" используются лексика и стилистические средства, отражающие стратегический характер текущих отношений между Кубой и Россией, но основанных на исторических связях дружбы.
\end{abstract}

\title{
Discursive Modelling of the Current Russian-Cuban Relations in News Media Texts of the Cuban News Agency "Prensa Latina” (“PL”)
}

\author{
Barcelay Ramírez Yarileisy
}

\begin{abstract}
The paper aims to identify lexical means of discursive modelling of the current Russian-Cuban relations (from 2000 till nowadays) in news media texts of the Cuban News Agency "Prensa Latina” ("PL”). Scientific originality of the study lies in the fact that the author for the first time considers the problem of discursive modelling of the current Russian-Cuban relations. The methods of discourse analysis and content analysis are applied, which makes it possible to reveal the Cuban journalists' constructive vision of the RussianCuban relations under the modern geo-political conditions. The following conclusions are justified: "PL" news media texts contain lexical and stylistic means emphasizing strategic importance of the Russian-Cuban relations based on historical friendship ties.
\end{abstract}

\section{Введение}

Актуальность темы исследования обусловлена, прежде всего, влиянием контента, представленного в “PL” официальном агентстве, широко признанном в странах Латинской Америки, - на создание благоприятного имиджа для Кубы и России в нынешних геополитических условиях, очищающего негативный международный имидж, намеренно представляемый об обоих правительствах в зарубежных цифровых СМИ. Кроме того, тема актуальна использованием лингвистических средств в политическом дискурсе медиатекстов цифровых медиа для воздействия на аудиторию, формирования общественного мнения и манипулирования общественным сознанием.

Настоящее исследование разработано на основе текущего сценария укрепления отношений между Кубой и Россией, восстановленных в 2000 году во время официального визита президента России В. Путина в Гавану. Постоянное текущее взаимодействие между Кубой, по-прежнему социалистической, и сегодняшней Россией, капиталистической, было представлено в СМИ, однако предполагается, что характер нынешних отношений между обоими государствами не складывается четко аналитическим путем, учитывая, что, во-первых, Гавана и Москва - сильные союзники, несмотря на разные политические и экономические модели; и во-вторых, Москва представляет собой важного экономического партнера Кубы, в то же время Гавана является важным стратегическим партнером Москвы в регионе Латинской Америки и Карибского бассейна. 
Для достижения заявленной цели решаются следующие задачи: во-первых, обосновать теоретическую базу исследования с учетом работ, посвященных изучению политического дискурса медиатекстов, особенно официальных цифровых СМИ, и их влияния на общество; во-вторых, проанализировать содержание и дискурс текстов и взаимосвязь лингвистической и экстралингвистической сторон текстов сообщений; в-третьих, выявить лексические средства дискурсивного конструирования современных российско-кубинских отношений в дискурсе сообщений, чтобы выделить новые важные качественные особенности нынешних российскокубинских отношений в условиях современных отношений между двумя странами. Анализ содержания онлайн-материалов проводился систематически в период с июня по сентябрь 2020 года.

Основными методами исследования являются дискурсивный анализ и контент-анализ. Дискурс-анализ позволил изучить лексические и семантические особенности материалов. С помощью метода тематического контент-анализа был определен список тем для поиска слов в контексте. На основе этого тематического списка были проанализированы 2 раздела официального сайта “PL”, которые включают следующие темы: новости (Европа, спорт, культура, наука, экономика) и специальные материалы (политика, экономика, спорт, культура, наука, хроники).

Теоретической базой исследования, наряду с трудами А. А. Грабельникова, Н. С. Гегеловой [1], Г. Н. Трофимовой [3], М. Кастельса [4], Г. Дженкинса [6], посвященными производству содержания цифровых медиатекстов, послужили публикации российских и зарубежных исследователей, в которых рассматривается вопрос практики политического дискурса медиатекстов [5; 10], медиаманипуляций новыми СМИ [2; 7] и их влияния на общество.

Практическая значимость данного исследования заключается в том, что его результаты могут быть использованы при подготовке курсов различных направлений теории языка, лексикологии, политической лингвистики, стилистики и т.д., а также при подготовке курсовых и научно-квалификационных работ, показывающих актуальное конструктивное видение языка медиатекстов, характеризующего отношения между Кубой и Россией в современных геополитических условиях.

\section{Роль политического дискурса цифровых медиатекстов в наше время}

Как известно, новая эволюционная логика, в которой сходятся медиа и технологии, уже позволяет нам обращаться к теории, связанной с производством медиатекстов в виртуальном пространстве [1; 3; 4; 6]. Сегодня цифровые СМИ являются основным инструментом формирования общественного мнения масс, однако в них используются такие стратегии, в том числе и манипулятивные, как дезинформация или производство фейковых новостей (от английского fake news). В этом смысле анализ политического дискурса медиатекстов и их влияния на общество продолжает оставаться приоритетным в XXI веке для исследователей из разных социальных сфер и из разных стран $[7 ; 8 ; 10]$. Их исследования связаны с практиками манипулирования общественным сознанием с помощью медиатекстов.

Именно по этой причине российские исследователи [2; 7] подчеркивают тесную взаимосвязь между политической жизнью и манипулированием СМИ, принимая во внимание, что целью политического манипулирования являются приобретение и удержание власти [7, р. 521].

Большую часть новостей, передаваемых в различных СМИ, если они посвящены политике, следует классифицировать как политический дискурс. «Для анализа политического дискурса особенно интересно то, что политические практики и действия являются одновременно дискурсивными практиками. Формы текста и речи имеют политическое значение и функции» (здесь и далее перевод автора статьи. - Б. Р. Я.) [5, р. 15]. Итак, считается необходимым проводить систематический анализ медиаконтента, особенно дискурса и содержания цифровых медиа. Следовательно, официальные СМИ, в особенности государственные, играют важную роль.

Государственные цифровые СМИ стремятся «сообщать», а не «манипулировать». Их ответственность перед обществом обязывает их распространять достоверные новости, которые противодействуют потоку «ложных» новостей, свободно циркулирующих в Интернете через различные группы мнений.

Кроме того, дискурс онлайн-сообщений “PL” играет важную роль в создании благоприятного международного политического имиджа для обеих стран с учетом той роли, которую Россия играет в международной политике и на Кубе как ее главный латиноамериканский союзник. Кроме того, это влияет на поддержание выгодных политических отношений между правительствами России и стран Латинской Америки.

“PL”, созданное на Кубе в 1959 году, имеет тот же статус: это престижное агентство в Латинской Америке имеет представительства в 32 странах, отвечающие за распространение и коммерциализацию текущей информации по различным темам на Кубе и в Карибском бассейне на разных языках. Независимо от политической повестки дня сообщения должны содержать надежную, поддающуюся проверке, прозрачную информацию с подходом, который гарантирует положительное влияние на общественность, поскольку ложное содержание сеет семена недоверия и намеренно убеждает аудиторию продвигать специфические источники информации [11]. Отсюда важность анализа медиадискурса, отражающего политический контекст нынешних российско-кубинских отношений в материалах “PL”.

\section{Анализ дискурса/содержания онлайн-материалов агентства “PL”}

Материалом исследования стали сообщения на испанском языке, опубликованные в разделах сайта "PL" [9]. Методом сплошной выборки было выявлено 453 сообщения (общим объемом 169160 знаков), в которых 
упоминалась Россия, опубликованных с января по июль 2020 года. Эти сообщения были выделены в данном исследовании в 3 тематические категории: политика, экономика, общество. С помощью контент-анализа были проанализированы внутренняя структура текста и его экстралингвистический контекст с учетом трех основных элементов: 1) тематика материала; 2) аргументация и 3) структура текста (описание идей), которые позволили осуществить дискурс-анализ: 1) морфосинтаксический анализ; 2) лексико-семантический анализ и 3) семантико-стилистический анализ.

Следует отметить, что в каждом из проведенных анализов содержание/дискурс изучается на основе трех основных элементов: взаимная политико-экономическая поддержка между Гаваной и Москвой с учетом политических конфликтов между Гаваной и Вашингтоном; характер нынешних российско-кубинских отношений с учетом политических и экономических интересов обоих государств; эмоциональная сторона, которая характеризует нынешние отношения с учетом исторических связей между двумя народами, независимо от политических интересов.

\section{Морфосинтаксический анализ дискурса/содержания онлайн-материалов агентства “PL”}

Морфосинтаксический анализ позволил узнать, что в веб-контенте агентства “PL” большое внимание уделяется темам, связанным с текущими событиями в России в различных сферах жизни общества. На синтагматическом уровне наблюдается, что медиатексты новостей “PL” содержат выражения, отражающие противостояние между «ними» (США) и «нами» (Россия / Куба / Венесуэла / Китай / Ближний Восток). Как в заголовке, так и в содержании следующей заметки видно противостояние:

Rusia rechaza bloqueo de EE.UU. y reafirma hermandad con Cuba, 02.05.2020. / Россия отвергает блокаду США и подтверждает братство с Кубой; Rusia: EE.UU. aprovecha la pandemia para instigar la confrontación, 13.05.2020. / Россия: США используют пандемию, чтобы спровоцировать конфронтацию; La Jornada: China, Rusia y la UE apoyan a la OMS en la lucha contra los ataques estadounidenses, 20.05.2020. / Ла-Хорнада: Китай, Россия и ЕС поддерживают ВОЗ в борьбе с атаками США; Rusia condena campaña de Occidente para dañar la imagen de Putin, 24.05.2020. / Россия осуждает кампанию Запада по нанесению ущерба имиджу Путина.

На синтагматическом уровне наблюдается, что при построении медиатекстов “PL” существуют основные синтагматические структуры и выражения, которые определяют нынешние российско-кубинские отношения. Об этом свидетельствует содержание следующих сообщений:

Rusia rechaza bloqueo de EE.UU. y reafirma hermandad con Cuba, 02.05.2020. / Россия отвергает блокаду США и подтверждает братство с Кубой; El canciller ruso, Serguei Lavrov, rechazó el bloqueo estadounidense y reafirmó la hermanad de su país con Cuba... / Министр иностранных дел России Сергей Лавров отверг блокаду США и подтвердил братство своей страны с Кубой; Vemos que los intentos de Estados Unidos de subordinar a América Latina a sus intereses geopolíticos están dirigidos a derrocar a los "gobiernos incómodos" en Cuba, Venezuela y Nicaragua... / Мы видим, что попытки США подчинить Латинскую Америку своим геополитическим интересам направлены на свержение «неудобных правительств» на Кубе, в Венесуэле и Никарагуа...; Estamos categóricamente en contra de esos pasos y expresamos nuestra solidaridad con nuestros amigos cubanos... / Мы категорически против этих шагов и выражаем солидарность с нашими кубинскими друзьями...

Очевидно, что эти фразы отражают идеологическую функцию текста, которая демонстрирует с позитивной стороны ценность нынешних российско-кубинских отношений, а также политическую поддержку между правительствами обеих стран.

С другой стороны, экономическое содержание “PL” позитивно отражает активное участие России в программе экономического развития Кубы до 2030 года. Точно так же эта категория с позитивной стороны подчеркивает роль правительства России в преодолении последствий для экономического сектора и социальные последствия пандемии Covid-19.

Морфосинтаксический анализ позволил выявить большое количество фраз с эмоциональной насыщенностью в содержании сообщений “PL” социального характера (научного, культурного, исторического и др.). Это отражает синтагматическая структура следующих заголовков:

Expertos de Rusia y Cuba debaten sobre ciencia en La Habana, 05.02.2020. / В Гаване эксперты из России и Кубы обсуждают науку; Rusia y la tradición viva de la Maslenitsa, март 2020 2. / Россия и живая традиция Масленицы; Gagarin: la era espacial tiene corazón optimista, anрель 2020 г. / Гагарин: у космической эры оптимистическое сердце; Rusia: Victoria sin derecho al olvido, 09.05.2020. / Россия: Победа без права быть забытым; Rusia pierde la condición de 'país del té' por alto consumo de café, 14.05.2020. / Россия теряет статус «чайной страны» из-за высокого потребления кофе.

Очевидно, что на сайте “PL” постоянный мониторинг ведется не только за политическими событиями, но и за общественными событиями, связанными с текущими событиями в России. Использование глагольных фраз и выражений в заголовке и в содержании текста демонстрирует идеологическую функцию сообщений “PL”, отражая ценность, которую они придают как истории России, так и историческим связям между двумя странами.

Анализ текстов на морфосинтаксическом уровне позволил выявить:

а) использование активного залога как в политических, так и в экономических сообщениях, так что действие глагола переходит на субъект. Очевидно, что смысловая нагрузка на субъекте подразумевает, с одной стороны, позицию России как международного политического лидера и ее постоянное противостояние с США и западными странами, а с другой стороны, позитивный имидж Путина в направлении его страны; 
б) сбалансированный набор характеристик, подчеркивающих характер нынешних российско-кубинских отношений, с использованием морфосинтаксической структуры «существительное + квалифицирующее прилагательное» с эмоционально-оценочными выражениями;

в) исторический смысл нынешних российско-кубинских отношений, подкрепленный историческими узами дружбы между двумя народами.

\section{Лексико-семантический анализ дискурса/содержания онлайн-материалов агентства “PL”}

Лексико-семантический анализ позволил узнать, что на структурном уровне тексты онлайн-сообщений “PL” представляют собой информационные тексты, структурированные вокруг ядра, четко выраженного в заголовке сообщения, за которым следует «вступление», или «лид». Лид содержит наиболее релевантный элемент новости в двух или трех строках. В тексте сообщений не повествуется о событии, а интерпретируются данные. Как правило, основная часть новостей заполнена дословными или перефразированными цитатами политических лидеров, государственных учреждений или официальных аккаунтов в социальных сетях, сообщающих об этом факте. В содержании “PL” систематически появляются комментарии или авторские хроники, которые в большинстве случаев в позитивном ключе затрагивают вопросы исторического или культурного события в России, а также текущую политическую ситуацию, подчеркивая политическую роль России и ее влияние на международной арене. Этот тип заметок имеет обширную структуру, и в их содержании выражаются оценочные и/или эмоциональные составляющие текста (и автора).

При анализе политических сообщений видно, что событие представлено максимально приближенным к реальности, что демонстрируется на лингвистическом уровне с использованием цитат в дискурсе. Такой лингвистический подход к представлению контента демонстрирует объективность и уверенность, но также выполняет политическую функцию, влияя на общественное мнение.

На синтагматическом уровне было выявлено большое количество повторяющихся фраз и словосочетаний, в большинстве случаев выделенных в тексте в кавычках, что помогает проследить лексико-семантическое значение политического и экономического дискурса. Например: Rusia rechaza falsificaciones sobre sus informes de la Covid-19, 12.05.2020. / Россия отвергает фейки в отчетах о Covid-19.

Пресс-секретарь МИД России М. Захарова заявила, что за последние три дня в западных публикациях прошел настоящий дождь статей (verdadera lluvia de artículos), посвященных предполагаемой манипуляции (supuesta manipulación) в разгар катастрофической ситуации в США... Пресс-секретарь напомнила, что эта кампания дезинформации (campaña de desinformación) присоединяется к другим подобным по таким вопросам, как предполагаемая победа США и Великобритании над немецким фашизмом, исключая Советский Союз.

Lluvia de artículos / дождь статей - это метафора, отражающая реальность медиавойны западных СМИ, направленных на то, чтобы нанести ущерб имиджу страны в отношении России. Эти СМИ постоянно публикуют новости, противоречащие информации официальных российских СМИ.

Campaña de desinformación / кампания дезинформации - это синтагматическая структура, значение которой противоположно социальной функции СМИ - информировать. В этом смысле западные СМИ дезинформируют массы вместо того, чтобы информировать, и отвлекают внимание от внутриполитической ситуации в таких странах, как США, с намерением сосредоточить внимание на ситуации в таких странах, как Россия или Китай.

Rusia: EE.UU. aprovecha la pandemia para instigar la confrontación, 13.05.2020. / Россия: США используют пандемию, чтобы спровоцировать конфронтацию.

...Estados Unidos refuerza la presión en los países que llevan a cabo una política exterior independiente... Se escuchan acusaciones infundadas contra China у Rusia... / США усиливают давление на страны, которые проводят независимую внешнюю политику... Раздаются необоснованные обвинения в адрес Китая и России.

Reforzar la presión / усиление давления - это клише, которое постоянно используется в выступлениях “PL" по поводу применения односторонних санкций и экономических репрессий США в отношении стран, не разделяющих их идеологию, таких как Куба, Венесуэла, Китай, Россия и др.

Rusia rechaza informe sobre injerencia en política británica, 21.07.2020. / Россия отвергает сообщение о вмешательстве в британскую политику.

Сегодня Россия отвергла данные доклада британского парламента о ее предполагаемом вмешательстве во внутреннюю политику Соединенного Королевства, назвав его 'русофобским и полностью ложным' ('rusofóbico y totalmente falso').

Rusofobia / русофобия - это идиоматический термин, который сегодня широко используется в кубинских и российских СМИ для характеристики политической позиции стран, испытывающих антипатию к России. В приведенных выше примерах четко прослеживается использование ярких фраз (в кавычках) с экспрессивноэмоционально-оценочными коннотациями, характеризующих и оценивающих отношения между Россией и США.

В политическом дискурсе “PL” постоянно сравнивается политическое поведение США, России и Китая, а также политическое влияние их лидеров. Процесс принятия политических решений Вашингтоном подвергается критике, а политическое влияние Москвы превозносится.

Следующие фрагменты демонстрируют некоторые фразеологизмы и идиоматические выражения, которые помогают понять национальный и культурный характер дискурса, особенно в кубинских государственных СМИ: Embajada rusa en Alemania rechaza acusaciones de ciberataque, 27.05.2020. / Посольство России в Германии отвергает обвинения в кибератаке. 
Esta es una 'historia trillada', se indica en una declaración que acusa a las autoridades alemanas de negarse a cooperar en la investigación del caso. / Это ‘банальная история’, - было сказано в заявлении, в котором немецкие власти обвиняются в отказе сотрудничать в расследовании этого дела.

Очевидно, что в речи “PL” многократно используются разговорные выражения с определенным эмоциональным фоном, который в то же время придает саркастический тон содержанию, манипулируя идеологической модальностью языка. Вот некоторые из идиоматических фраз, разговорных выражений и клише, наиболее часто используемых для отражения политического имиджа США:

Egoísmo incurable / неизлечимый эгоизм: глагольная фраза, которая относится к отсутствию человеческих ценностей и солидарности в период эпидемии Covid-19, во время которой не исчезли односторонние экономические санкции, введенные США против таких стран, как Россия и Куба.

Máquina de fabricar mentiras / машина для изготовления лжи; сатраña mediática tejida / сплетенная в СМИ кампания; guion de Hollywood / голливудский сценарий; mirar hacia el otro lado de las gradas / взгляд с другой стороны трибун: это идиомы, клише, метафоры, относящиеся к распространению ложных новостей о действиях правительства России и Китая в период ситуации с пандемией Covid-19, а также распространению в западных СМИ искаженных новостей об участии России в конфликте стран Ближнего Востока (Сирия, Ливия, Иран). Вся эта ситуация отражается как «сценарий», подготовленный и действующий для того, чтобы нанести ущерб имиджу России и привлечь внимание мировой общественности к этой стране, в то время как США пребывают в постоянном внутреннем политическом хаосе.

Historia trillada / банальная история: эта фраза-клише относится к чему-то общеизвестному. История, выбранная для определенной цели. В данном случае это обвинение России в организации кибератаки со стороны парламента Германии. Эта история создана в разгар эпидемиологической ситуации по Covid-19 как отвлекающая тактика: с намерением ослабить имидж России.

В то же время в материалах “PL” очевиден позитивный подход к содержанию политических дебатов, особенно когда они относятся к руководству Путина и принятию решений в стране. Об этом свидетельствуют следующие сообщения: Rusia y las adaptaciones de su Constitución al siglo XXI, 29.06.2020. / Россия и адаптация ее Конституции к XXI веку.

Консультации по предлагаемым конституционным изменениям были инициативой президента В. Путина (una iniciativa del presidente V. Putin), который считал, что для того, чтобы придать массовый смысл и подлинную легитимность изменениям, они должны получить поддержку большинства населения (el apoyo mayoritario de la población).

Putin llama a todos a votar en el referendo de reforma constitucional, 30.06.2020. / Путин призывает всех проголосовать на референдуме по конституционной реформе.

En vísperas del día fundamental de la consulta popular, Putin señaló que cuando en Rusia todos están juntos, incluso en una situación crítica, pueden resolver las tareas más difíciles. / Накануне основополагающего дня всенародного опроса Путин отметил, что когда в России все вместе, даже в критической ситуации, можно решить самые сложные задачи...

Путин был уверен (Putin se mostró confiado), что при голосовании граждане России будут думать, прежде всего, о своих близких, исходя из ценностей, которые объединяют правду и справедливость, уважение к работающему человеку и предыдущим поколениям.

Повторные сообщения привлекают внимание к роли Путина в развитии и изменении российской нации. Они постоянно используют синтагматические конструкции, отражающие идеологическую функцию текста, например:

La victoria del sí reafirma la confianza en él de la ciudadanía, al ser visto como factor de estabilidad nacional. / Победа «да» подтверждает доверие граждан к нему [Путину], поскольку он рассматривается как фактор национальной стабильности.

El mandatario es visto como símbolo de estabilidad para esta nación en las últimas dos décadas. / По мнению экспертов, президент рассматривается как символ стабильности этой страны в последние два десятилетия.

Очевидно, что “PL” использует выражения, которые выполняют идеологическую и пропагандистскую функции, для создания положительного образа президента России В. Путина. Точно так же сообщения по теме «Общество» показывают хорошие результаты России и ее лидеров во время международной эпидемиологической ситуации с Covid-19. Всегда используются заголовки с синтагматической структурой, которые противопоставляют количество инфекций положительным достижениям во время эпидемии. Например: Primer ministro ruso destaca estabilidad en situación con Covid-19, 20.05.2020. / Премьер-министр России подчеркнул стабильность ситуации с Covid-19; Rusia con más de 16 mil altas médicas de Covid-19 en 48 horas, 21.05.2020. / В России за 48 часов было выписано более 16 тысяч пациентов с Covid-19; Rusia con cifra de recuperados por encima de contagiados de Covid-19, 10.06.2020. / В России число выздоровевших превысило число инфицированных Covid-19.

При интерпретации ценности российско-кубинских отношений выявляются синтагматические структуры, отражающие политический союз между Гаваной и Москвой, политический интерес отношений между двумя странами независимо от идеологических разногласий и в то же время историческую связь, характеризующую дружеские отношения двух народов в современных условиях. Следующие отрывки демонстрируют это: Россия отвергает блокаду США и подтверждает братство с Кубой, 05.02.2020.

Министр иностранных дел России Сергей Лавров отверг блокаду США и подтвердил братство своей страны с Кубой... Санкции, примененные Вашингтоном против Кубы, демонстрируют, что, пытаясь задушить экономику острова, США сознательно нарушают права человека. <...> Мы категорически против подобных шагов 
и выражаем солидарность с нашими кубинскими друзьями... Сейчас Куба является приоритетным партнером России в латиноамериканском регионе и в Карибском бассейне. Наше многоплановое сотрудничество основано на прочных традициях дружбы и сотрудничества, на объективном совпадении наших интересов и ориентировано на построение лучшего будущего. Общая цзель укрепления российско-кубинского стратегического партнерства подтверждается регулярными контактами на высшем уровне... Тот факт, что президент Кубы Мигель ДиасКанель Бермудес посещает Россию для участия в торжественных мероприятиях, символичен к 75-летию разгрома фашизма. Мы видим в этом еще одно подтверждение уз братства между нашими народами... Вместе с нашими кубинскими друзьями мы продолжаем строить модель долгосрочного взаимовыгодного сотрудничества... Мы с оптимизмом смотрим на будущее российско-кубинских отношений, которые имеют для нас большую ценность. Мы знаем, что у наших друзей такое же видение.

Очевидно, что в речи “PL” примечательно использование клише, квалифицирующих прилагательных, словесных комбинаций, которые создают определенный эмоциональный фон, отражая текущие отношения между двумя народами. По случаю празднования 60-летия двусторонних отношений между Кубой и Россией неоднократно появлялись сообщения, характеризующие состояние нынешних отношений как отличное, очень благоприятное, на высоком уровне.

Día de Rusia: apreciar la memoria histórica y velar por futuro común, 12.06.2020. / День России: беречь историческую память и обеспечивать общее будущее.

Мы способствуем развитию дружеских и конструктивных отношений (las relaciones amistosas y constructivas) со всеми нашими партнерами. Un énfasis especial hacemos en el fortalecimiento de la cooperación con los que, a pesar de estar geográficamente lejos, tenemos el espíritu de hermandad. / Мы уделяем особое внимание укреплению сотрудничества с теми, кто, несмотря на географическую удаленность, хранит дух братства... Среди таких стран, конечно же, Куба. Остров Свободы - наш стратегический партнер (nuestros socios estratégicos) в регионе Латинской Америки и Карибского бассейна; наши узы дружбы (nuestros lazos de amistad) достигли наивысшего уровня развития за всю свою современную историю.

В политическом дискурсе “PL” отражено мнение политических лидеров обеих стран, которые уверяют, что на Кубе и в России преобладают взаимная симпатия между их народами, стремление к справедливости и равноправию, желание обеих стран к продолжению суверенного пути развития, единство в понимании фундаментальных ценностей и истории.

\section{Семантико-стилистический анализ дискурса/содержания онлайн-материалов агентства “PL”}

С использованием тематического контент-анализа исследовательский материал (453 сообщения) объемом 160169 знаков был обработан с помощью программы Microsoft Word (ориентированной на обработку текста) для поиска слов и выражений в определенном ранее контексте, которые характеризуют российскокубинские отношения в содержании материалов “PL”. В результате проведенного расширенного поиска, комбинирующего выражения и словесные сочетания с наибольшей частотой появления в содержании, в ходе семантико-стилистического анализа выявлен определенный набор лексем и фраз-клише, которые неоднократно использовались для передачи информации о политических конфликтах и о характере нынешних российско-кубинских отношений: кампания дезинформации в СМИ (20), обвинения в предполагаемой российской дезинформации/манипуляции/виновности/причастности/вмешательстве (20), разжигание конфронтации (17), провокационные/дестабилизирующие действия (14), односторонние санкции (12), сильное давление (11), симметричный ответ (9), манипуляции со СМИ (6), двойные стандарты (5), национальная стабильность (7), взаимовыгодное сотрудничество (5), экономическое сотрудничество (7), российско-кубинское стратегическое партнерство (8), российско-кубинские отношения воспринимаются с оптимизмом (5), дипломатические/двусторонние отношения в отличном состоянии (6), политический диалог на высоком уровне (5), исторические узы братства и дружбы (9).

На экстралингвистическом уровне поддержка Москвы Гаваной перед лицом политических конфликтов и роль кубинских государственных СМИ в формировании положительного имиджа России интерпретируются как противопоставление дезинформационной кампании западных СМИ о России.

Особое внимание уделяется текущим событиям в России, но не только политического характера, но также культурного, исторического и социального. На экстралингвистическом уровне подразумеваются приоритет, который Москва представляет для Гаваны, благодарность Кубы за солидарное отношение, которое Россия всегда проявляла к Кубе в трудные времена, а также близость кубинского народа к русскому народу, его культуре, языку, истории.

\section{Заключение}

Таким образом, при анализе дискурсивного конструирования современных российско-кубинских отношений в содержании онлайн-материалов агентства «Пренса Латина» мы пришли к следующим выводам: в кубинских государственных СМИ весьма заметно наличие выражений, применяемых для представления противостояния США и другие страны: Россия, Куба, Венесуэла, Китай, Ближний Восток, а также постоянно присутствуют 
метафоры для отречения от главного политического врага Гаваны - Вашингтона. Однако при обращении к своему главному европейскому политическому союзнику - Москве подход к содержанию положительный.

При анализе содержания сообщений “PL” были замечены, с одной стороны, попытка сформировать позитивный образ России в мире, подчеркивая ее геополитическое влияние и лидерство В. Путина; с другой стороны, стратегический характер дипломатических отношений, но основанных на крепких исторических связях, дружбе, симпатии, понимании и уважении, с оптимизмом смотрящих в будущее. Нынешние отношения между Кубой и Россией представлены с помощью лексических средств, в состав которых входят выражения и фразыклише, отражающие положительные качественные особенности российско-кубинских отношений в условиях современных отношений между двумя странами: стратегические, прагматичные, современные, взаимовыгодные отношения; отношения взаимного доверия между правительствами обеих стран; политические отношения на высоком уровне; традиционно дружеские отношения; Куба и Россия - партнеры-друзья.

В качестве перспектив дальнейшего исследования рассматривается возможность провести анализ дискурса/содержания материалов российского агентства международной информации «РИА Новости», чтобы впоследствии провести сравнительный анализ лексических средств дискурсивного конструирования, используемых обоими информационными агентствами.

\section{Список источников}

1. Грабельников А. А., Гегелова Н. С. Экранная коммуникация и визуализация журналистики: монография. Тверь: Твер. гос. ун-т, 2019. 334 с.

2. Никитина К. В. Политический дискурс СМИ и его особенности, создающие предпосылки для манипуляции общественным сознанием // Управление общественными и экономическими системами. 2006. № 2. С. 1-7.

3. Трофимова Г. Н. Языковой вкус интернет-эпохи в России. Функционирование русского языка в Интернете: концептуально-сущностные доминанты: монография. Изд-е 2-е, испр. и доп. М.: РУДН, 2009. 436 с.

4. Castells M. El impacto de Internet en la sociedad: una perspectiva global. Madrid: OpenMind, 2014.25 p.

5. Dijk T. A. van, Mendizábal I. R. Análisis del discurso social y político. Quito: Editorial Abya Yala, 1999. 168 p.

6. Jenkins H. Convergence Culture: Where Old and New Media Collide // Revista Austral de Ciencias Sociales. 2011. № 20. P. 129-133.

7. Kultysheva O., Fisenko A. B. Ways of Manipulating Public Consciousness with Modern Media: An Analysis of the Russian Regional Publications // Media Education (Mediaobrazovanie). 2019. Vol. 59. № 4. P. 518-537.

8. Lee E., Tandoc E. When News Meets the Audience: How Audience Feedback Online Affects News Production and Consumption // Human Communication Research. 2017. Vol. 43. № 4. P. 436-449.

9. Prensa Latina [Электронный ресурc]. URL: https://www.prensa-latina.cu/ (дата обращения: 14.09.2020).

10. Reunanen E., Kunelius R. The Transformation of Communicative Power into Political Power // Communication Theory. 2020. Vol. 30. № 1. P. 1-20.

11. Shu K., Sliva A., Wang S., Tang J., Liu H. Fake news detection on social media: A data mining perspective // ACM SIGKDD Explorations Newsletter. 2017. Vol. 19. № 1. P. 22-36.

\section{Информация об авторах | Author information}

\section{RU Барселай Рамирес Ярилейси}

${ }^{1}$ Российский университет дружбы народов, г. Москва

EN Barcelay Ramírez Yarileisy ${ }^{1}$

${ }^{1}$ Peoples' Friendship University of Russia, Moscow

${ }^{1}$ yaribarcelay@gmail.com

\section{Информация о статье | About this article}

Дата поступления рукописи (received): 03.12.2020; опубликовано (published): 10.02.2021.

Ключевые слова (keywords): политический массмедийный дискурс; дискурсивное конструирование российско-кубинских отношений; дискурс-анализ; контент-анализ; mass media political discourse; discursive modelling of the Russian-Cuban relations; discourse analysis; content analysis. 